\title{
Optimization of the Cutting Regime in the Turning of the AISI 316L Steel for Biomedical Purposes Based on the Initial Progression of Tool Wear
}

\author{
Ricardo del Risco-Alfonso ${ }^{1}\left(\mathbb{D}\right.$, Roberto Pérez-Rodríguez ${ }^{2, *} \mathbb{B}$, Patricia del Carmen Zambrano Robledo ${ }^{3}$, \\ Marcelino Rivas Santana ${ }^{4}$ and Ramón Quiza ${ }^{4}$ (D)
}

1 CEEFREP Study Centre, University of Camagüey, Camagüey 74650, Cuba; ricardo.delrisco@reduc.edu.cu 2 CAD/CAM Study Centre, University of Holguin, Holguin 80100, Cuba

3 División de Estudios de Posgrados, Universidad Autónoma de Nuevo León, Nuevo León 64260, Mexico; patricia.zambranor@uanl.edu.mx

4 CEFAS Study Centre, University of Matanzas, Matanzas 40100, Cuba; marcelino.rivas@umcc.cu (M.R.S.); ramon.quiza@umcc.cu (R.Q.)

* Correspondence: roberto.perez@uho.edu.cu; Tel.: +53-24-482678

Citation: del Risco-Alfonso, R.; Pérez-Rodríguez, R.; Zambrano Robledo, P.d.C.; Rivas Santana, M.; Quiza, R. Optimization of the Cutting Regime in the Turning of the AISI 316L Steel for Biomedical Purposes Based on the Initial Progression of Tool Wear. Metals 2021, 11, 1698. https://doi.org/10.3390/ met11111698

Academic Editors: Sergey N. Grigoriev and Badis Haddag

Received: 14 September 2021

Accepted: 20 October 2021

Published: 25 October 2021

Publisher's Note: MDPI stays neutral with regard to jurisdictional claims in published maps and institutional affiliations.

Copyright: (c) 2021 by the authors. Licensee MDPI, Basel, Switzerland. This article is an open access article distributed under the terms and conditions of the Creative Commons Attribution (CC BY) license (https:/ / creativecommons.org/licenses/by/ $4.0 /)$.

\begin{abstract}
The development of biomedical devices has improved the quality of life for millions of people. The increase in life expectancy generates an increase in the demand for these devices. One of the most used materials for these purposes is $316 \mathrm{~L}$ austenitic stainless steel due to its mechanical properties and good biocompatibility. The objective of the present investigation was to identify the dependence between the main cutting force, the initial speed of the tool wear, the surface roughness, and the parameters of the cutting regime. Based on these dependencies, a multi-objective optimization model is proposed to minimize the energy consumed and initial wear rate, as well as to maximize productivity, maintaining the surface roughness values below those established by the ISO 5832-1 standard. The wear of the cutting tool was measured on a scanning electron microscope. For the optimization process, a genetic algorithm based on NSGA-II (Non-nominated Sorting Genetic Algorithm) was implemented. The input variables were the cutting speed and the feed in three levels. The cutting force and surface roughness were set as restrictions. It is concluded that the mathematical model allows for the optimization of the cutting regime during dry turning and with the use of MQL (Minimum Quantity Lubrication) with BIDEMICS JX1 ceramic tools (NTK Cutting Tools, Wixom, MI, USA), of AISI 316 L steel for biomedical purposes. Pareto sets and boundaries allow for choosing the most appropriate solution according to the specific conditions of the workshop where it is applied, minimizing the initial progression of tool wear and energy consumed, and maximizing productivity by guaranteeing the surface roughness values established for these types of parts according to the standard.
\end{abstract}

Keywords: optimization; ceramic cutting tool; 316L; wear; NSGA-II

\section{Introduction}

The development achieved in the field of orthopedic surgery has required the production of biomedical devices, which have led to an improvement in the quality of life of millions of people [1]. At the same time, the increase in the life expectancy of the population generates an increase in the demand for these devices, with the aim of minimizing the impacts of accidents and the occurrence of age-related injuries. One of the most used materials for these purposes is $316 \mathrm{~L}$ austenitic stainless steel due to its properties of high resistance to corrosion, low cost, and good bio-compatibility [2].

These steels report poor machinability due to their high tendency to work harder; toughness and relatively low thermal conductivity [3]; and high tensile strength, which induce high cutting forces and the generation of high temperatures. These factors considerably increase tool wear, build-up edge formation, and increase the surface roughness [4-6]. 
Stainless steels are traditionally machined at cutting speeds ranging from 150 to $300 \mathrm{~m} / \mathrm{min}$, although these materials show good behavior at higher cutting speeds $[7,8]$. This aspect is remarkable due to the influence that surface roughness has on the behavior of austenitic stainless steel used as a biomaterial $[9,10]$.

The search for new materials for cutting tools for machining these materials is of interest to the biomedical industry sector. In this sense, studies are appreciated in the dry turning of AISI 304 and AISI 316 steels using multi-layer-coated and cemented carbide tools [11], where it was demonstrated that the cutting speed has a significant effect on the values of the surface roughness. Similarly, studies [12] are identified with the objective of monitoring the wear of coated cemented carbide tools and surface roughness in the turning of AISI 316L steel under different lubrication conditions.

In the case of the use of ceramics as a material for cutting tools, it has been found that alumina successfully machines stainless steels [13]. Furthermore, there is little evidence on the machining of stainless steels with the use of ceramic cutting tools [14-16]. The limitations are mainly focused on the studies of the failure mechanisms of the tool, as well as its influence on the surface roughness. The studies analyzed show that ceramic tools can be used with satisfactory results in machining austenitic stainless steels.

There is a direct relationship between the parameters of the cutting regime and the behavior of the initial wear of the cutting tool, alongside its useful life. However, this singularity has received less attention compared to the other two regions of the wear curve $[17,18]$. At the same time, to evaluate this initial wear of the tool, it is necessary to apply multi-objective optimization [19] of the parameters of the cutting regime [20] in order to reduce its effects. To solve multi-objective optimization problems, a large number of tools have been developed [21]. Among the most used techniques are genetic algorithms, the most widely used being the genetic algorithm of the Non-nominated Sorting Genetic Algorithm (NSGA-II).

The review of the scientific literature confirms that the use of ceramic tools in the machining of stainless steels and specifically AISI 316L has been little discussed. The BIDEMIC JX1 ceramic tool was specially designed for machining heat-resistant alloys [22]; however, there are no studies that relate and optimize the parameters of the cutting regime with the initial wear of these tools for the machining of these types of steels.

The main objective of this research study is to identify the dependence between the main cutting force, the initial speed of wear of the cutting tool, the surface roughness, and the parameters of the cutting regime in turning AISI 316L [15] steel for biomedical purposes. From these dependency relationships, a multi-objective optimization model based on the NSGA-II algorithm [23] is proposed to minimize the energy consumed and initial rate of wear of the cutting tool, and to maximize productivity, maintaining the values of surface roughness below those established in the ISO 5832-1 standard.

\section{Materials and Methods}

The procedure used for the investigation is shown in Figure 1. The following were selected as response variables: (a) surface roughness due to its influence on the biocompatibility of the material; (b) the initial wear of the cutting tool due to its incidence on the surface roughness; and (c) the values of the cutting forces as an indicator of the machinability of the material.

For the investigation, an AISI 316L steel bar with a chemical composition according to the ISO 5832-1 standard was used. The average hardness obtained with a Wilson Rockwell durometer was 148 HRB. The cutting tool used was a "BIDEMICS" RNGN 120700E004 JX1 (NTK Cutting Tools, Aichi, Japan) from the ceramic family without coating (12.7 $\mathrm{mm}$ in diameter and $7.94 \mathrm{~mm}$ in thickness), specially designed for machining heat-resistant alloys. The insert was placed in a Kennametal DRGNR-164D-KC3 NA4 (Kennametal, Pittsburgh, PA, USA) holder with top flange and screw fixation. As a machine tool, a HAAS ST10 CNC (HAAS Automation, Oxnard, CA, USA) lathe (Figure 2) was used with a maximum capacity of $356 \times 406 \mathrm{~mm}, 11.2 \mathrm{~kW}$ of power, and $6000 \mathrm{rpm}$ in the spindle. A Kistler 9257B 
dynamometer (Kistler Group, Winterthur, Switzerland) was used to measure cutting forces and a Mitutoyo SJ-201P (Mitutoyo Corporation, Kanagawa, Japan) roughness tester to measure surface roughness.

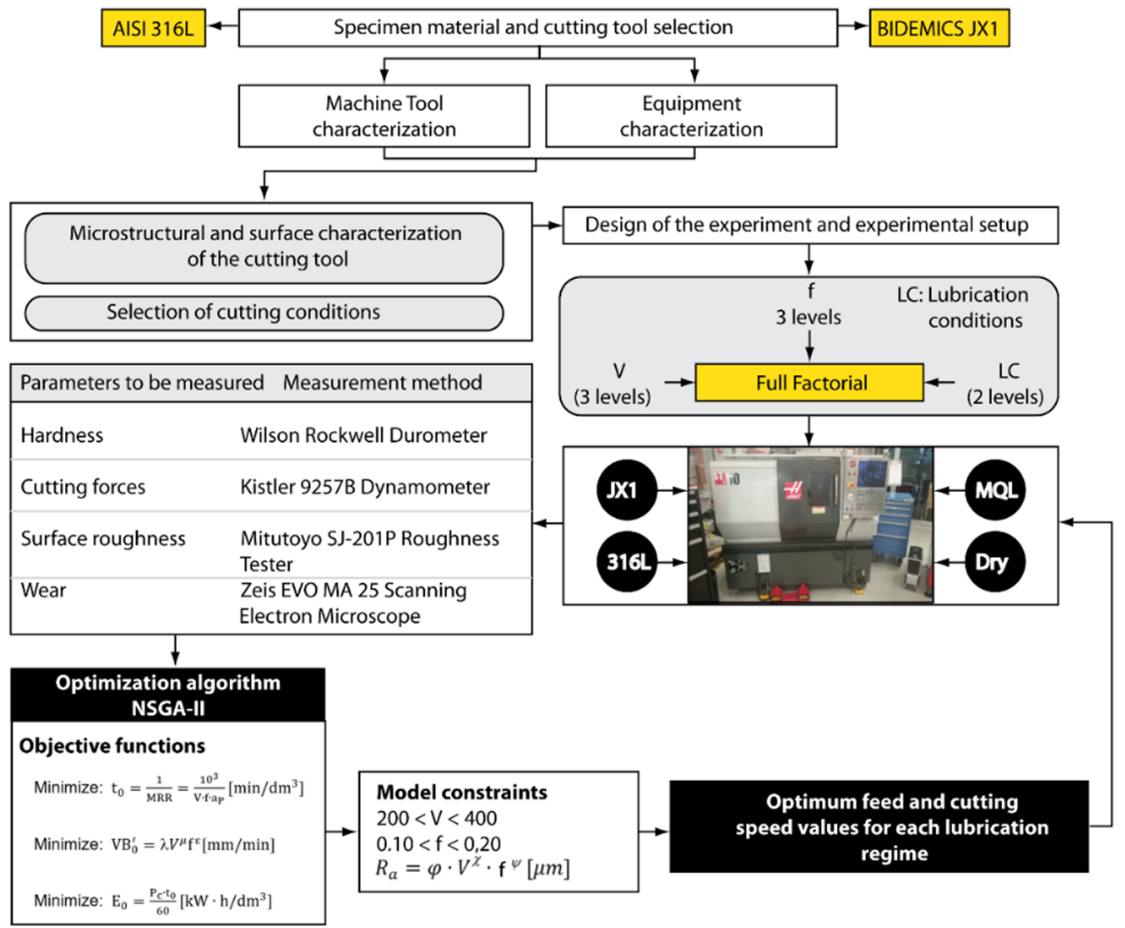

Figure 1. Procedure used in the investigation ( $\mathrm{t}_{0}$ is the unit cut-off time, $\mathrm{V}$ is the cutting speed, $\mathrm{VB}_{0}^{\prime}$ is the initial wear progression, $E_{0}$ is the unit energy of cutting, $f$ is the feed speed, Ra is the surface roughness). NSGA-II: Non-nominated Sorting Genetic Algorithm. BIDEMICS JX1: ceramic tools.

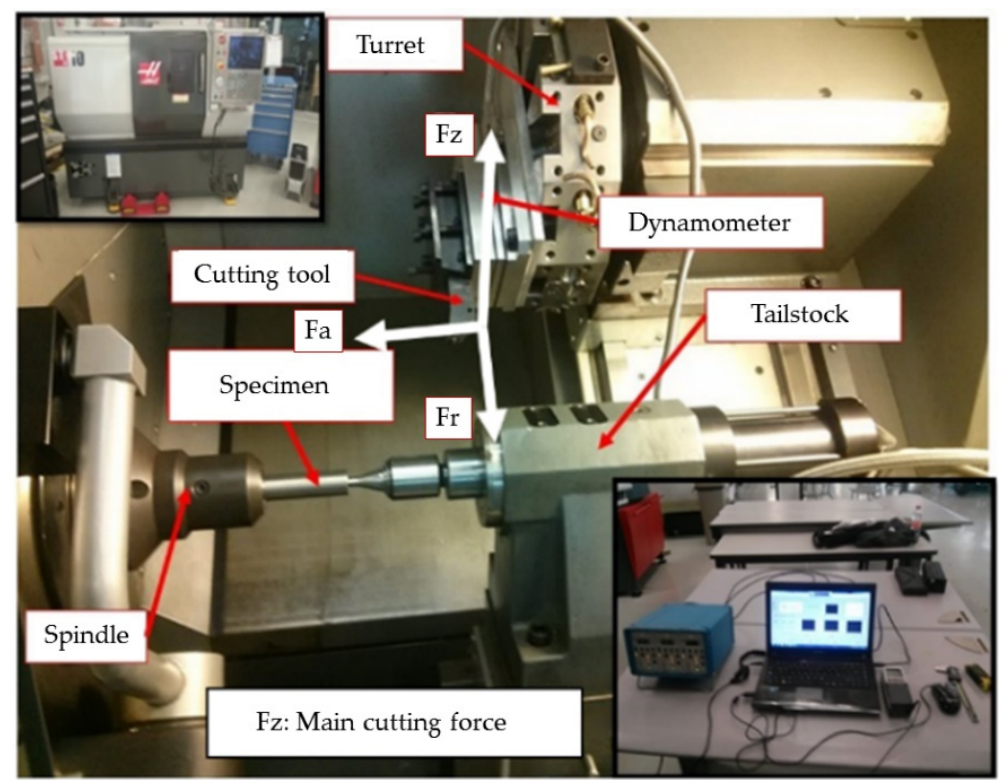

Figure 2. CNC machine tool used to perform wear tests on the cutting tools. CNC: Computer Numerical Control. Fz: main cutting force. Fa: axial cutting force. Fr: radial cutting force.

As a test specimen, an austenitic stainless steel AISI 316L bar, $25 \mathrm{~mm}$ in diameter and $120 \mathrm{~mm}$ in length, was used, mounted in the CNC machine tool between the nozzle and point. The depth of cut $\left(a_{p}\right)$ was kept constant and equal to $0.5 \mathrm{~mm}$. As an output variable, 
the Fz was measured. Wear (VB) was measured on the relief surface of the cutting tool with the help of a Zeiss EVO MA25 scanning electron microscope (Zeiss Microscopy, Jena, Germany) and, finally, the Ra was measured with a Mitutoyo SJ-201P roughness tester (Mitutoyo Corporation, Kanagawa, Japan). For the MQL lubrication regime, a TRI-COOL MD-1 lubricant (Trico Oilers, Berkshire, UK) was employed and a vegetable type was used in both ferrous and non-ferrous metal-cutting operations.

\section{Objective Function and Optimization with NSGA-II}

In the present research study, we proposed to minimize the initial progression of the cutting tool wear and energy consumed, as well as to maximize productivity and maintain the surface roughness values below the established limit. These parameters were selected because they represent the three main components in the cost of a machining process $[24,25]$. Productivity is defined by unit machining time, which can be defined as the inverse of the material removal rate. Therefore, the optimization problem can be stated as follows:

The objective functions are:

$$
\begin{gathered}
\text { Minimize : } \mathrm{t}_{0}=\frac{1}{\mathrm{MRR}}=\frac{10^{3}}{\mathrm{~V} \cdot \mathrm{f} \cdot \mathrm{a}_{\mathrm{P}}}\left[\mathrm{min} / \mathrm{dm}^{3}\right] \\
\text { Minimize }: \mathrm{VB}_{0}^{\prime}=\lambda V^{\mu} \mathrm{f}^{\varepsilon}[\mathrm{mm} / \mathrm{min}] \\
\text { Minimize }: \mathrm{E}_{0}=\frac{\mathrm{P}_{\mathrm{c}} \cdot \mathrm{t}_{0}}{60}\left[\mathrm{~kW} \cdot \mathrm{h} / \mathrm{dm}^{3}\right]
\end{gathered}
$$

where MRR is the material removal rate, the terms $\lambda, \mu$, and $\varepsilon$ are regression coefficients, while $P_{c}$ is the cutting power given by:

$$
\mathrm{P}_{\mathrm{C}}=\frac{\mathrm{F}_{\mathrm{z}} \cdot \mathrm{V}}{6 \cdot 10^{4}}[\mathrm{~kW}]
$$

where $\mathrm{F}_{\mathrm{c}}$ is the main cutting force, which is related to the cutting parameters for:

$$
\mathrm{F}_{\mathrm{c}}=\alpha \mathrm{V}^{\beta} \mathrm{f}^{\gamma}[\mathrm{N}]
$$

where $\alpha, \beta$, and $\gamma$ are regression coefficients. Equations (1)-(3) are subject to restrictions:

$$
\begin{gathered}
200 \mathrm{~m} / \mathrm{min} \leq \mathrm{V} \leq 400 \mathrm{~m} / \mathrm{min} \\
0.1 \mathrm{~mm} / \mathrm{rev} \leq \mathrm{f} \leq 0.20 \mathrm{~mm} / \mathrm{rev} \\
\mathrm{R}_{\mathrm{a}}=\varphi \cdot \mathrm{V}^{\chi} \cdot \mathrm{f}^{\psi} \leq 0.5[\mu \mathrm{m}]
\end{gathered}
$$

where $\varphi, \chi$, and $\psi$ are regression coefficients.

\section{Results and Discussion}

A chemical composition study was carried out on the BIDEMICS RNGN 120700E004 JX1 (NTK Cutting Tools, Aichi, Japan) insert (Figure 3). The results are shown in Table 1, verifying that the chemical composition is similar in both areas. Therefore, the insert is shown to be uncoated. Each one underwent a visual inspection of the cutting edge with the help of the Olympus SZH microscope (Olympus Corporation, Tokyo, Japan) in order to verify the surface integrity. 

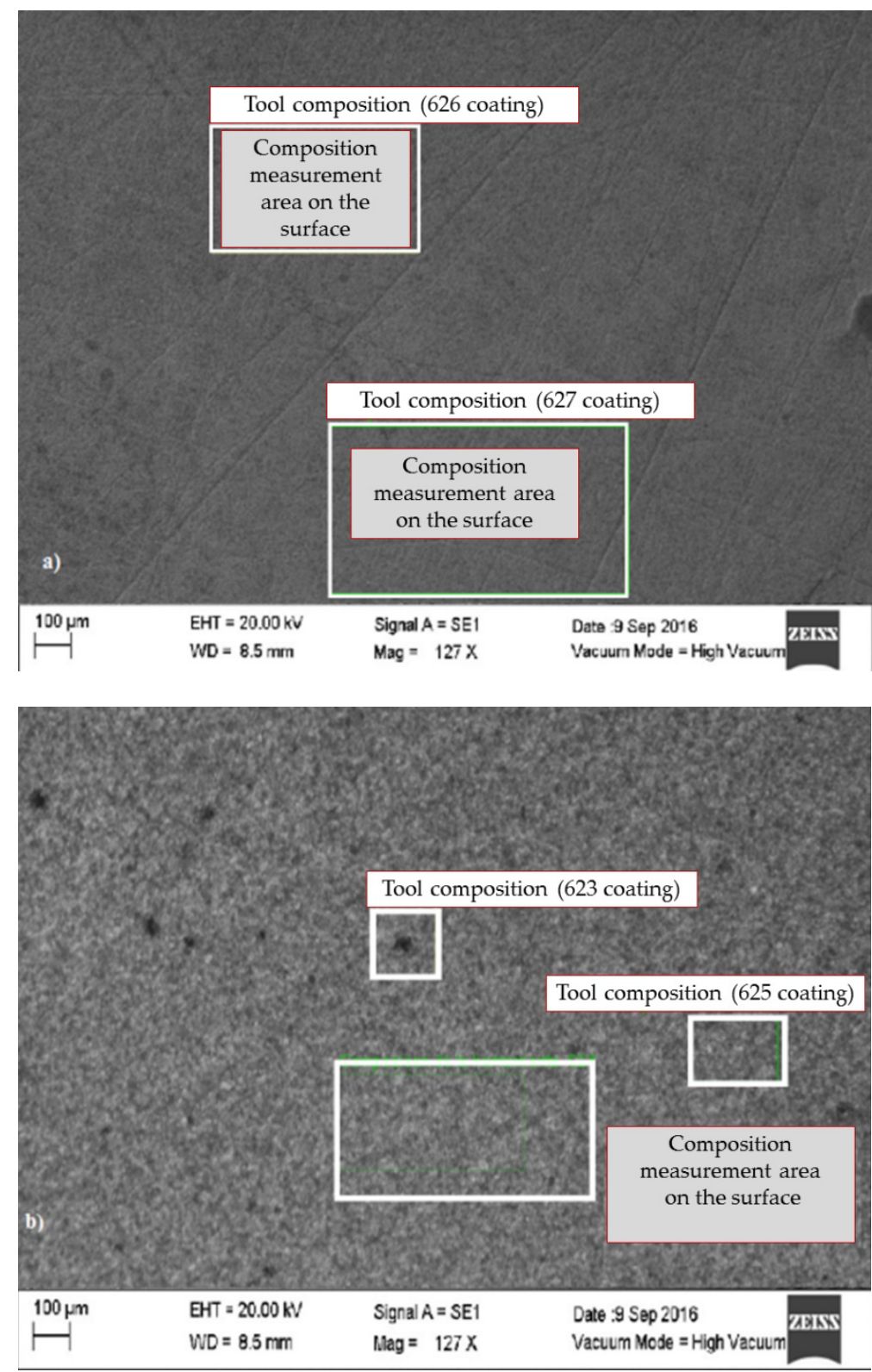

Figure 3. Microstructure of the tool with 127X magnification: (a) external zone and (b) internal zone. EHT: Electron High Tension. WD: Working Distance.

Table 1. Chemical composition of the cutting tool.

\begin{tabular}{lccccc}
\hline & \% W & \% O & \% Al & \% C & \% Zr \\
\hline External Zone & 55.23 & 18.78 & 16.12 & 6.4 & 3.45 \\
Internal Zone & 56.22 & 17.94 & 17.33 & 4.92 & 3.57 \\
\hline
\end{tabular}

The experiment was developed for a dry (1) turning operation and with the use of MQL (-1). The cutting speed (V) in three levels $(200,300$, and $400 \mathrm{~m} / \mathrm{min} ; 1,0$, and -1$)$ and the advance (f) in three levels $(0.1,0.15$, and $0.2 \mathrm{~mm} / \mathrm{rev} ; 1,0$, and -1$)$ were taken as independent variables and three replications were made of each run (Table 2). 
Table 2. Experimental results using the complete factorial array. No.: Number of the trials. LC: lubrication conditions. VB: flank wear. $\mathrm{F}_{\mathrm{Z}}$ : main cutting force. f: feed speed. Ra: surface roughness.

\begin{tabular}{|c|c|c|c|c|c|c|c|c|c|c|c|c|c|}
\hline \multicolumn{4}{|c|}{ Input Parameters } & \multicolumn{3}{|c|}{ Output Parameters } & \multicolumn{4}{|c|}{ Input Parameters } & \multicolumn{3}{|c|}{ Output Parameters } \\
\hline No. & $\mathbf{V}$ & $\mathrm{f}$ & LC & VB & $\mathbf{R a}$ & $F_{z}$ & No. & $\mathbf{V}$ & f & LC & VB & $\mathbf{R a}$ & $F_{z}$ \\
\hline 1 & 0 & -1 & 1 & 0.077 & 0.30 & 248.17 & 28 & 0 & -1 & 1 & 0.076 & 0.41 & 240.30 \\
\hline 2 & 1 & 1 & -1 & 0.044 & 0.38 & 290.97 & 29 & 1 & -1 & 1 & 0.096 & 0.33 & 220.81 \\
\hline 3 & 1 & 1 & 1 & 0.075 & 0.54 & 340.11 & 30 & -1 & 0 & -1 & 0.055 & 0.48 & 290.72 \\
\hline 4 & -1 & 0 & 1 & 0.060 & 0.55 & 310.98 & 31 & 0 & 0 & 1 & 0.074 & 0.49 & 288.98 \\
\hline 5 & 0 & -1 & -1 & 0.054 & 0.30 & 229.22 & 32 & -1 & -1 & 1 & 0.063 & 0.57 & 289.99 \\
\hline 6 & -1 & -1 & 1 & 0.062 & 0.53 & 290.87 & 33 & 1 & 0 & 1 & 0.091 & 0.40 & 285.01 \\
\hline 7 & -1 & 1 & 1 & 0.050 & 0.67 & 383.81 & 34 & -1 & 0 & 1 & 0.061 & 0.58 & 319.90 \\
\hline 8 & 1 & 0 & 1 & 0.080 & 0.38 & 280.70 & 35 & 1 & 0 & -1 & 0.050 & 0.34 & 222.40 \\
\hline 9 & 0 & 1 & 1 & 0.064 & 0.66 & 348.49 & 36 & 0 & 1 & -1 & 0.049 & 0.42 & 290.26 \\
\hline 10 & 1 & -1 & 1 & 0.097 & 0.30 & 224.27 & 37 & 0 & -1 & -1 & 0.052 & 0.30 & 237.05 \\
\hline 11 & -1 & -1 & -1 & 0.046 & 0.47 & 242.89 & 38 & 1 & 1 & 1 & 0.078 & 0.52 & 345.55 \\
\hline 12 & 0 & 1 & -1 & 0.048 & 0.43 & 291.04 & 39 & 0 & 0 & -1 & 0.041 & 0.44 & 260.38 \\
\hline 13 & 0 & 0 & -1 & 0.053 & 0.41 & 261.82 & 40 & 0 & 1 & 1 & 0.073 & 0.64 & 351.78 \\
\hline 14 & -1 & 1 & -1 & 0.041 & 0.52 & 330.37 & 41 & 0 & 1 & -1 & 0.049 & 0.44 & 288.00 \\
\hline 15 & 1 & 0 & -1 & 0.049 & 0.33 & 215.91 & 42 & -1 & 1 & 1 & 0.061 & 0.66 & 379.04 \\
\hline 16 & -1 & 0 & -1 & 0.044 & 0.49 & 288.87 & 43 & 1 & -1 & -1 & 0.064 & 0.26 & 205.63 \\
\hline 17 & 1 & -1 & -1 & 0.058 & 0.25 & 200.28 & 44 & 0 & 0 & 1 & 0.072 & 0.51 & 292.54 \\
\hline 18 & 0 & 0 & 1 & 0.074 & 0.52 & 280.48 & 45 & -1 & -1 & 1 & 0.064 & 0.55 & 225.29 \\
\hline 19 & -1 & -1 & -1 & 0.048 & 0.48 & 229.63 & 46 & 0 & -1 & 1 & 0.076 & 0.37 & 244.65 \\
\hline 20 & 1 & 1 & 1 & 0.087 & 0.50 & 344.89 & 47 & -1 & -1 & -1 & 0.030 & 0.46 & 233.31 \\
\hline 21 & -1 & 1 & -1 & 0.037 & 0.51 & 344.18 & 48 & -1 & 0 & -1 & 0.038 & 0.49 & 285.02 \\
\hline 22 & 0 & 0 & -1 & 0.051 & 0.42 & 263.77 & 49 & 1 & -1 & 1 & 0.088 & 0.31 & 223.08 \\
\hline 23 & 0 & -1 & -1 & 0.050 & 0.32 & 231.41 & 50 & -1 & 0 & 1 & 0.060 & 0.54 & 314.86 \\
\hline 24 & -1 & 1 & 1 & 0.058 & 0.68 & 384.66 & 51 & 1 & 0 & -1 & 0.068 & 0.33 & 218.83 \\
\hline 25 & 0 & 1 & 1 & 0.070 & 0.68 & 346.43 & 52 & 1 & 0 & 1 & 0.082 & 0.42 & 284.35 \\
\hline 26 & 1 & 1 & -1 & 0.048 & 0.40 & 292.39 & 53 & 1 & 1 & -1 & 0.071 & 0.37 & 296.17 \\
\hline 27 & 1 & -1 & -1 & 0.056 & 0.29 & 202.39 & 54 & -1 & 1 & -1 & 0.041 & 0.53 & 332.12 \\
\hline
\end{tabular}

\subsection{Study of the Initial Progression of the Cutting Tool Wear}

From the cutting tool wear values obtained and considering that the machining length was constant (100 $\mathrm{mm}$ for each cutting pass under both lubrication conditions), the initial progression of wear could be defined for lubrication conditions. This allowed for obtaining the equations that define it (Table 3).

Table 3. Models of the initial progression of the tool wear. MQL: Minimum Quantity Lubrication. $\mathrm{VB}_{0}{ }_{0}$ : initial wear progression.

\begin{tabular}{ccc}
\hline Lubrication Regime & $\begin{array}{c}\text { Equation of the Initial } \\
\text { Progression of Tool Wear }\end{array}$ & $\mathbf{R}^{\mathbf{2}}$ \\
\hline Dry & $\mathrm{VB}_{0}^{\prime}=\frac{\mathrm{V}^{1.52} \cdot \mathrm{f}^{0.820}}{3.25 \cdot 10^{3}}$ & 0.99 \\
$\mathrm{MQL}$ & $\mathrm{VB}_{0}^{\prime}=\frac{\mathrm{V}^{1.42} \cdot \mathrm{f}^{0.911}}{2.33 \cdot 10^{3}}$ & 0.92 \\
\hline
\end{tabular}

Figure 4 shows how the initial progression of tool wear for both lubrication conditions increased with the increasing cutting speed, this being the factor that has the greatest impact. This corresponds to the theory of metal cutting [18], where it is observed that the cutting tool wear is lower during machining using the MQL. 


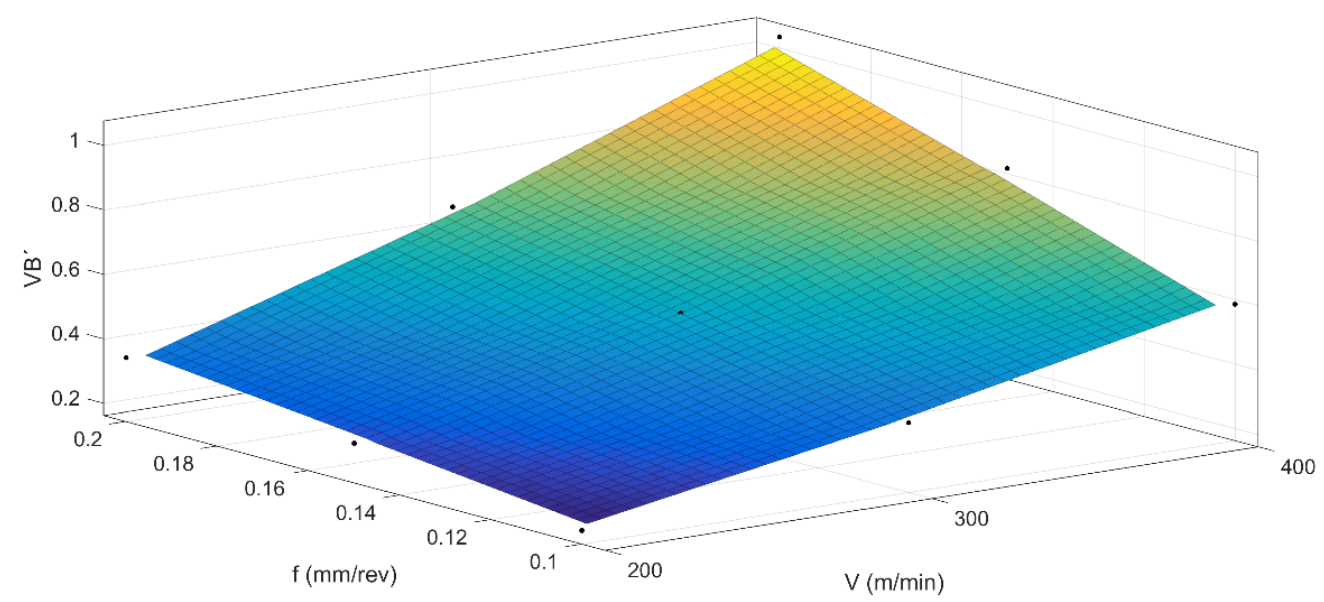

(a)

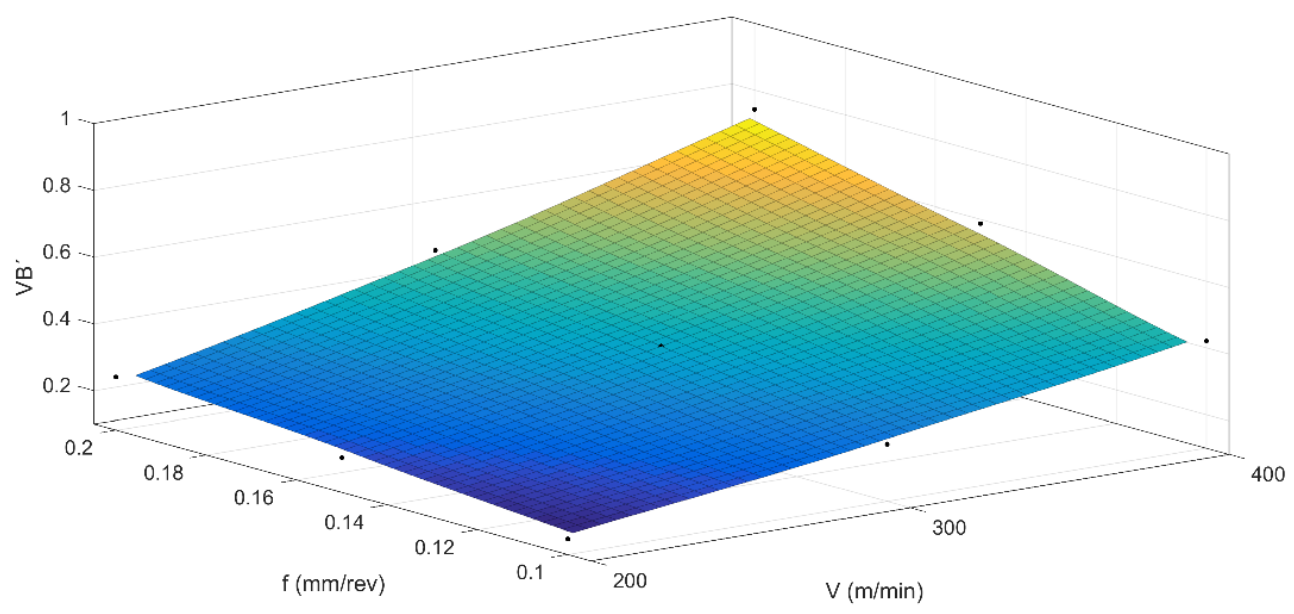

(b)

Figure 4. Behavior of the initial wear progression for (a) MQL (Minimum Quantity Lubrication) machining and (b) dry machining.

\subsection{Evaluation of the Wear of the Cutting Tool on the Relief Surface}

The flank wear (VB) of the inserts was carried out after machining throughout the operation $(100 \mathrm{~mm})$ for each combination of the variables of feed speed, cutting speed, and type of lubrication. Wear was measured on the incidence surface since it is the surface that most influences surface roughness, as shown by the studies carried out by Kumar et al. [26] and Labidi et al. [27].

In Figure 5a,b, the magnitude of the wear of the cutting tool on the incidence surface is shown for the cutting speed of $200 \mathrm{~m} / \mathrm{min}$ and feed speed of $0.1 \mathrm{~mm} / \mathrm{rev}$ for dry machining and with MQL, respectively. It can be seen that the insert that was used with MQL had a better behavior in terms of wear. It is also observed that the magnitude of wear (VB) was lower in the case of machining with MQL. In the case of dry machining, the appearance of material detachment in the cutting tool was also identified on the attack surface. This detachment occurred, fundamentally, in a small area where the first contact of the cutting tool with the specimen occurred. This corresponds to that reported by other studies of Mohd-Ali et al. [28], Mohd-Ali et al. [29], and Ahmad-Azhar et al. [30]. 

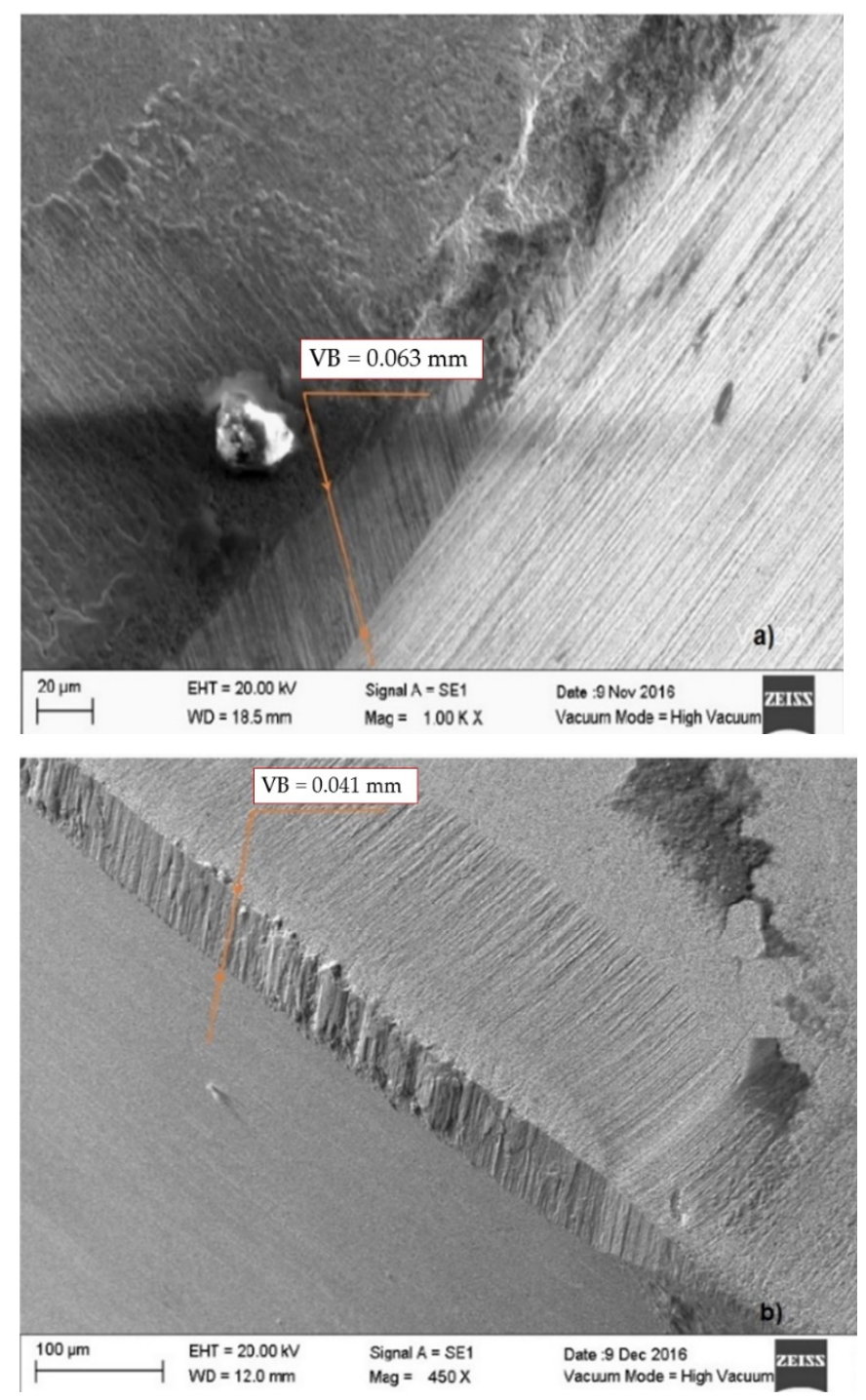

Figure 5. Wear on the incidence surface of the cutting tool for $V=200 \mathrm{~m} / \mathrm{min}$ and $\mathrm{f}=0.1 \mathrm{~mm} / \mathrm{rev}$ : (a) dry and (b) with MQL.

Figure $6 \mathrm{a}, \mathrm{b}$ shows the wear of the cutting tool on the incidence surface for the cutting speed of $200 \mathrm{~m} / \mathrm{min}$ and feed speed of $0.2 \mathrm{~mm} / \mathrm{rev}$ for the dry machining and MQL, respectively. As in the previous case, the insert in the machining with MQL had a better performance and less wear was observed on the cutting tool. If the wear areas are compared for the minimum cutting speed, with the minimum and maximum values of the feed rate, it can be concluded that in the case of dry machining and with MQL, there was practically no variation in wear. Therefore, the behavior is very similar, evidencing the little influence of the feed rate on it. 

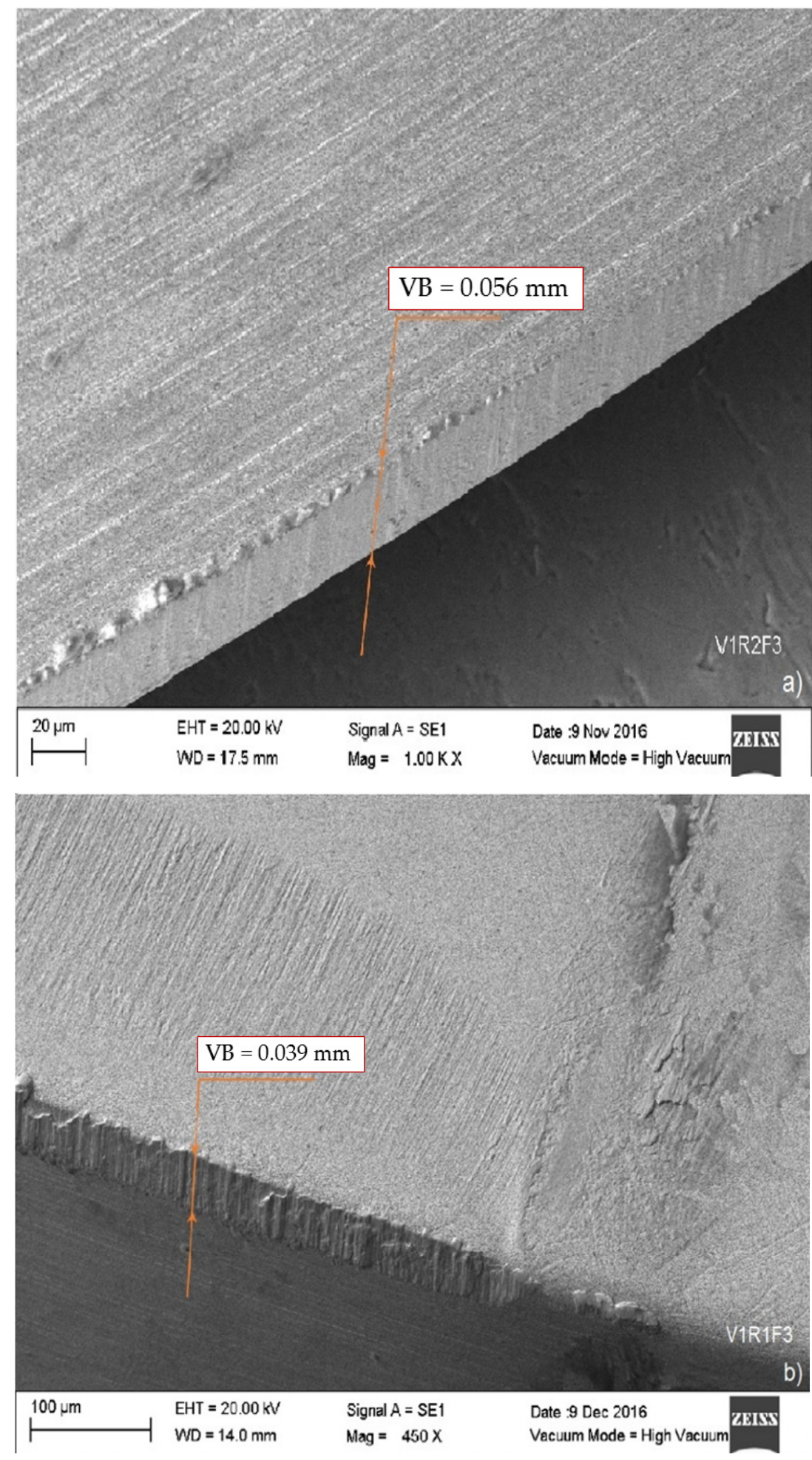

Figure 6. Wear on the incidence surface of the cutting tool for $V=200 \mathrm{~m} / \mathrm{min}$ and $\mathrm{f}=0.1 \mathrm{~mm} / \mathrm{rev}$ : (a) dry and (b) with MQL.

Figure $7 \mathrm{a}, \mathrm{b}$ show the wear of the cutting tool on the incidence surface for the cutting speed of $400 \mathrm{~m} / \mathrm{min}$ and feed speed $0.1 \mathrm{~mm} / \mathrm{rev}$ of the dry machining and with MQL, respectively. As can be seen, the magnitude of wear increased with increasing cutting speed, indicating a better behavior for the insert working with MQL, whose wear magnitude was lower. 


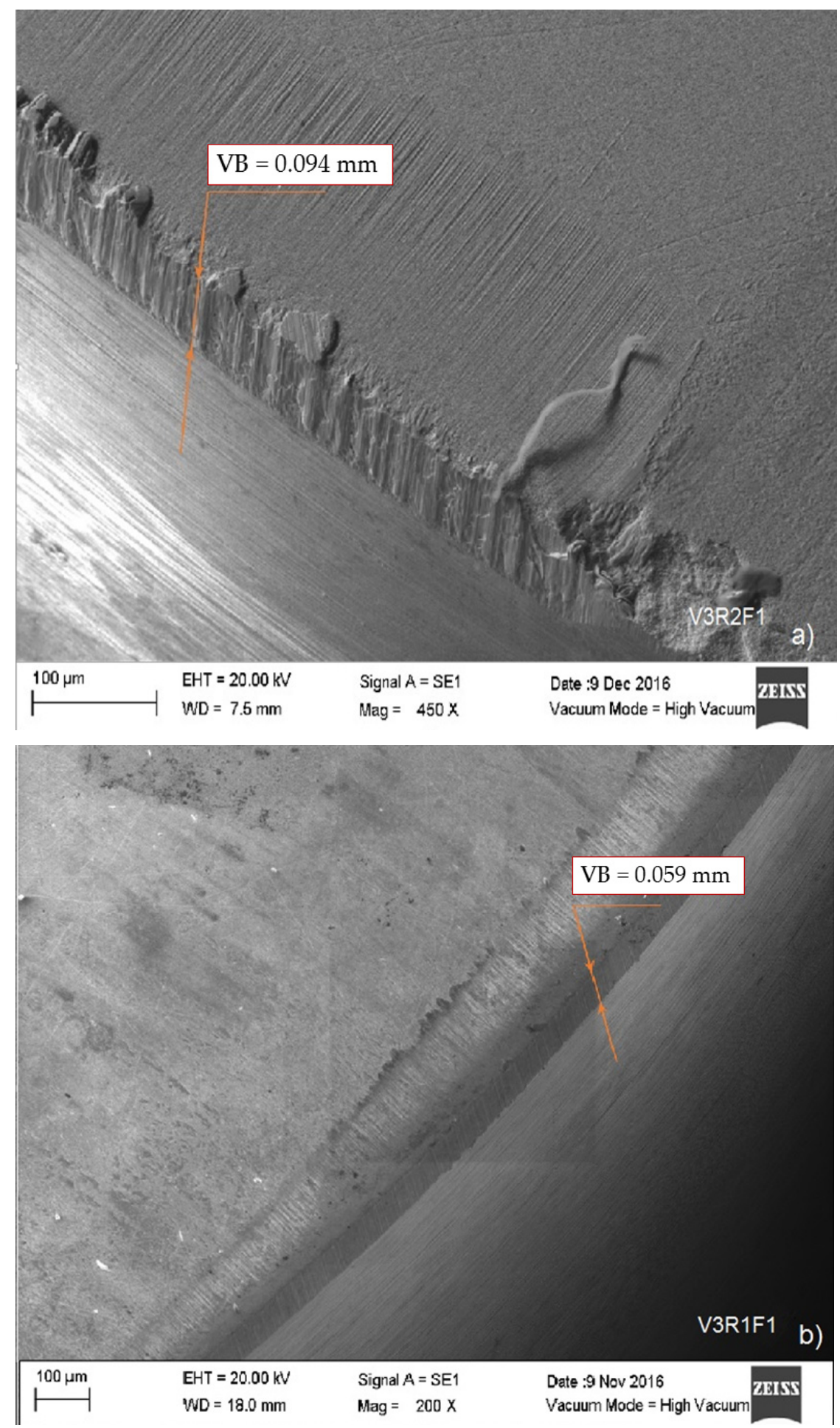

Figure 7. Wear on the incidence surface of the cutting tool for $\mathrm{V}=400 \mathrm{~m} / \mathrm{min}$ and $\mathrm{f}=0.1 \mathrm{~mm} / \mathrm{rev}$ : (a) dry and (b) with MQL.

Figure $8 \mathrm{a}, \mathrm{b}$ show the wear of the cutting tool for the cutting speed of $400 \mathrm{~m} / \mathrm{min}$ and feed rate $0.2 \mathrm{~mm} / \mathrm{rev}$ for the dry machining and with MQL, respectively. It can be seen that, concerning the lower cutting speed by varying the feed rate, the wear was practically unchanged. However, when compared with the cutting speed, the variation in wear was significant, which shows that the cutting speed in these tools is the factor that most influences the wear. It can be seen that, for all cases, the predominant wear on the incidence surface was the abrasive wear. 

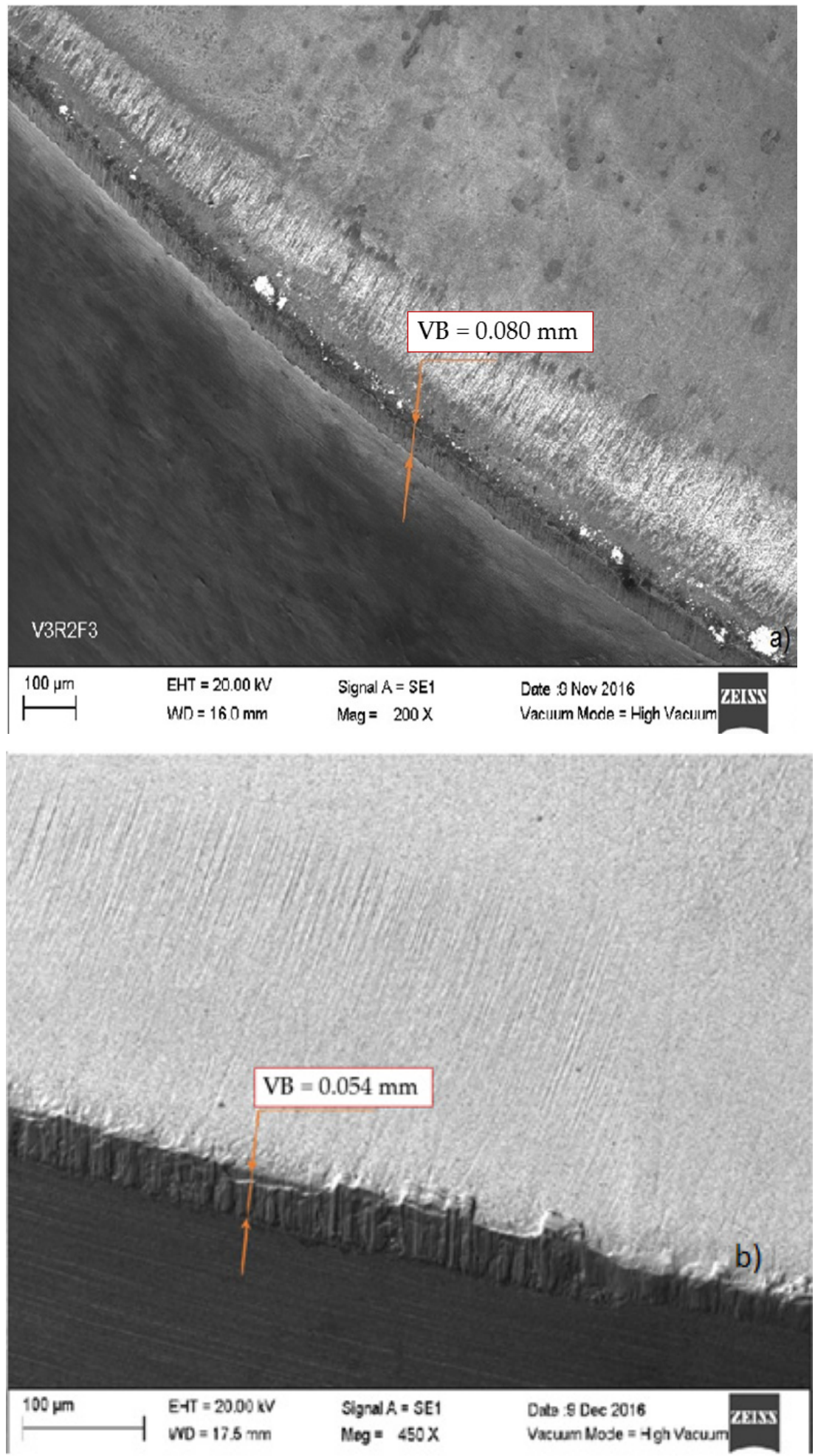

Figure 8. Wear on the incidence surface of the cutting tool for $\mathrm{V}=400 \mathrm{~m} / \mathrm{min}$ and $\mathrm{f}=0.1 \mathrm{~mm} / \mathrm{r}$ : (a) dry and (b) with MQL.

\subsection{Cutting Regime Optimization}

The optimization was carried out using the so-called a posteriori approach, where no information is provided on the preferences between the different targets before running the optimization [23]. This method returns a set of non-dominated solutions called Pareto fronts. In the present study, the NSGA-II genetic classification algorithm was selected [31]. 
To test the convergence of the Pareto front obtained, 30 repetitions were carried out for each problem. In both cases, a population of 5000 solutions and a maximum of 20,000 generations were used. As a frontal quality metric, hyper-volume was selected since it evaluates both the diversity and convergence of the obtained set [32].

Once the optimization had been carried out, the graphical representations of the Pareto set (Figure 9a) and Pareto front (Figure 9b) for dry machining were obtained, which allowed for choosing the most appropriate solution according to the specific conditions from the workshop. Firstly, it can be observed that the Pareto front formed a special curve, where the values of the main time and cutting energy increased simultaneously when the initial progression of the wear of the cutting tool decreased.

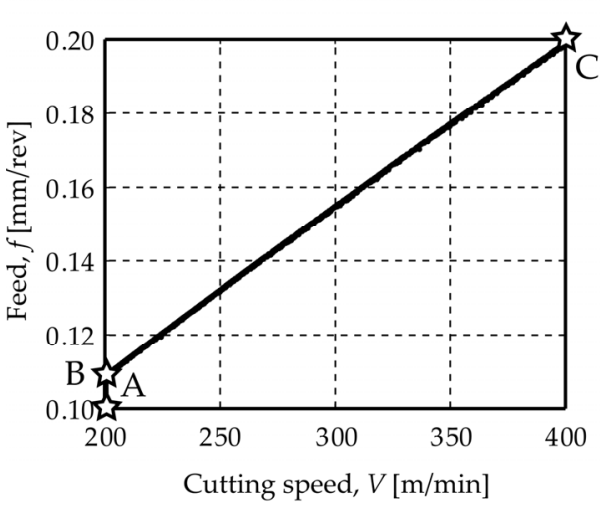

a) Pareto set

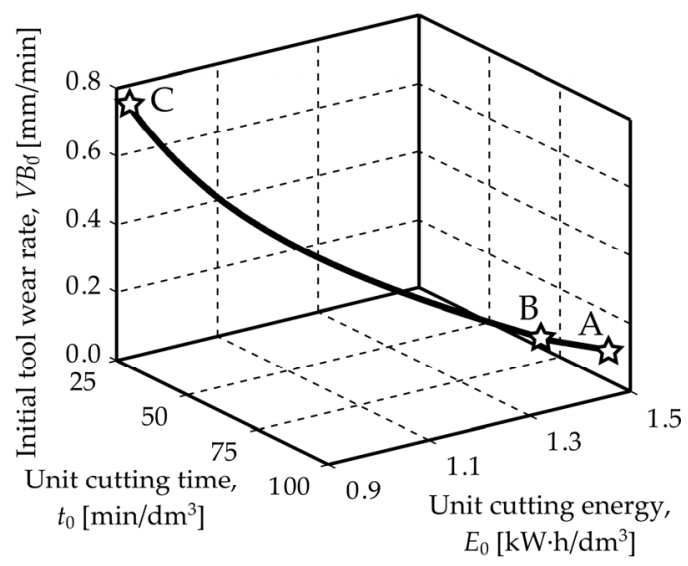

b) Pareto front

Figure 9. Values obtained in the optimization for dry machining. (a) graph of the Pareto set, (b) graph of the Pareto front (A, B and C: most relevant solutions for the selection of machining parameters).

For dry machining, the reference point was selected at $\tau_{0}=100 \mathrm{~min} / \mathrm{dm}^{3}, \mathrm{E}_{0}=1.5 \mathrm{kWh} / \mathrm{dm}^{3}$, and $\mathrm{VB}_{0}^{\prime}=0.8 \mathrm{~mm} / \mathrm{min}$. With these parameters, the mean value of the Pareto frontal hypervolume, with a confidence of $95 \%$, was in the interval $17.46 \pm 0.02$, which corresponds to a coefficient of variation of $0.3 \%$. This result indicates a high coincidence of the obtained fronts, thus the results are close enough to the true Pareto front to be used for practical purposes. Two areas can be appreciated. The first zone (AB interval) corresponded to the value of the lowest cutting speed, with feed speed values that increased from its minimum to the value where the maximum feasible surface roughness value of the surface was reached (according to the value that was set as a restriction). In the second zone (interval B-C), both cutting parameters increased at the same time, maintaining the surface roughness at its maximum feasible value (Table 4 ).

Table 4. Relevant solutions for dry machining.

\begin{tabular}{ccccccc}
\hline \multirow{2}{*}{ Solution } & \multicolumn{2}{c}{ Variables } & \multicolumn{3}{c}{ Objectives } & Restriction \\
\cline { 2 - 7 } & $\begin{array}{c}\mathbf{V} \\
{[\mathbf{m} / \mathbf{m i n}]}\end{array}$ & $\begin{array}{c}\mathbf{F} \\
{[\mathbf{m m} / \mathbf{r e v}]}\end{array}$ & $\begin{array}{c}\mathbf{t}_{\mathbf{0}} \\
{\left[\mathbf{m i n} / \mathbf{d m}^{3}\right]}\end{array}$ & $\begin{array}{c}\mathbf{E}_{\mathbf{0}} \\
{\left[\mathbf{k W} \cdot \mathbf{h} / \mathbf{d m}^{3}\right]}\end{array}$ & $\begin{array}{c}\mathbf{V B}_{0}^{\prime} \\
{[\mathbf{m m} / \mathbf{m i n}]}\end{array}$ & $\begin{array}{c}\mathbf{R}_{\mathbf{a}} \\
{[\boldsymbol{\mu m}]}\end{array}$ \\
\hline $\mathrm{A}$ & 200 & 0.10 & 100.0 & 1.44 & 0.146 & 0.47 \\
$\mathrm{~B}$ & 200 & 0.11 & 90.9 & 1.38 & 0.158 & 0.50 \\
$\mathrm{C}$ & 400 & 0.20 & 25.0 & 0.92 & 0.741 & 0.50 \\
\hline
\end{tabular}

Regarding the dry machining, the graphical representations of the Pareto set (Figure 10a) and Pareto front (Figure 10b) were obtained for machining with MQL, which allowed for choosing the most appropriate solution according to the specific shop conditions for this lubrication regime. It was observed that when using the MQL, there was also a correspondence between the increase in the unit cutting time and the unit cutting energy (with the corresponding decrease in the wear rate of the cutting tool). 


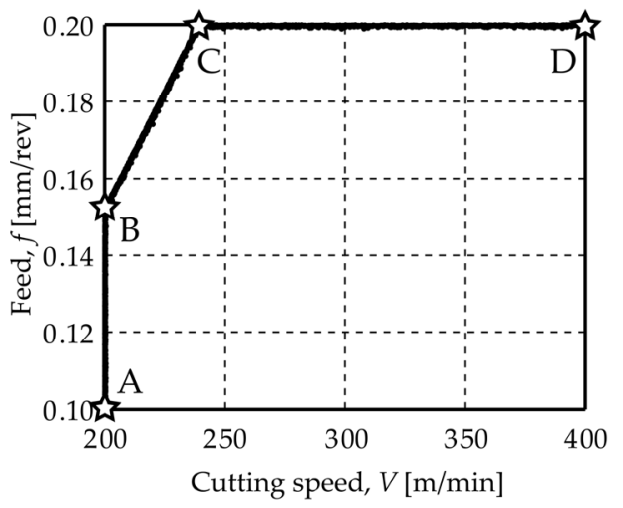

a) Pareto set

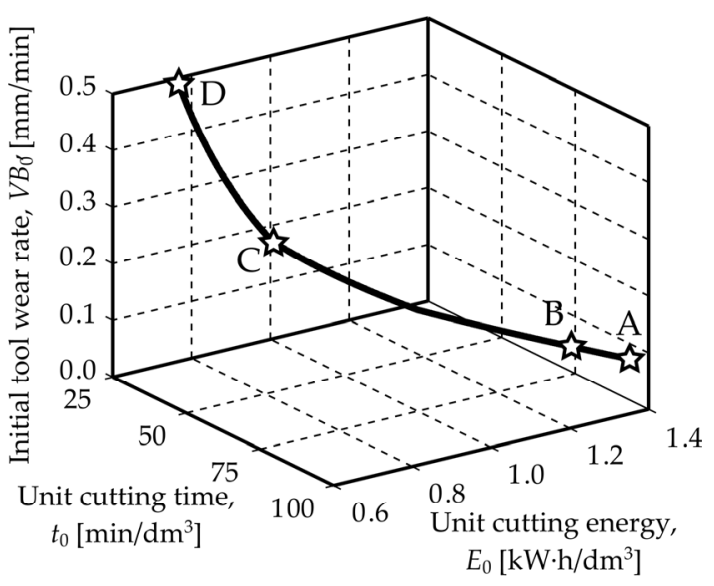

b) Pareto front

Figure 10. Values obtained in the optimization for machining with MQL. (a) graph of the Pareto set, (b) graph of the Pareto front (A, B, C and D: most relevant solutions for the selection of machining parameters).

For the case of machining with MQL, the hypervolume was calculated with reference to the point $\mathrm{t}_{0}=100 \mathrm{~min} / \mathrm{dm}^{3}, \mathrm{E}_{0}=1.4 \mathrm{kWh} / \mathrm{dm}^{3} \mathrm{y}$, and $\mathrm{VB}_{0}^{\prime}=0.5 \mathrm{~mm} / \mathrm{min}$. The resulting value was $12.86 \pm 0.01$ for a confidence level of $95 \%$, corresponding to a coefficient of variation of $0.2 \%$. Here, there was also a good convergence with the true Pareto front.

Three zones could be identified in the solutions obtained. The first zone (interval A-B) corresponded to the lowest value of the cutting speed. In this zone, the value of the speed of advance increased from its minimum value to the point where the surface roughness reached its limit of feasibility. The second subset contained the solutions where the surface roughness reached its maximum allowed value. In this case, the cutting speed and feed speed increased simultaneously until reaching their upper limit. Finally, the third zone was comprised of solutions where the feed speed was kept at its maximum value, while the cutting speed increased to its upper limit. This increase corresponded to a decrease in surface roughness and all this can be seen in Table 5 .

Table 5. Relevant solutions for MQL machining.

\begin{tabular}{ccccccc}
\hline \multirow{2}{*}{ Solution } & \multicolumn{2}{c}{ Variables } & \multicolumn{3}{c}{ Objectives } & Restriction \\
\cline { 2 - 7 } & $\begin{array}{c}\mathbf{V} \\
{[\mathbf{m} / \mathbf{m i n}]}\end{array}$ & $\begin{array}{c}\mathbf{F} \\
{[\mathbf{m m} / \mathbf{r}]}\end{array}$ & $\begin{array}{c}\mathbf{t}_{\mathbf{0}} \\
{\left[\mathbf{m i n} / \mathbf{d m}^{\mathbf{3}}\right]}\end{array}$ & $\begin{array}{c}\mathbf{E}_{\mathbf{0}} \\
{\left[\mathbf{k W} \cdot \mathbf{h} / \mathbf{d m}^{\mathbf{3}}\right]}\end{array}$ & $\begin{array}{c}\mathbf{V B}_{0}^{\prime} \\
{[\mathbf{m m} / \mathbf{m i n}]}\end{array}$ & $\begin{array}{c}\mathbf{R}_{\mathbf{a}} \\
{[\boldsymbol{\mu} \mathbf{m}]}\end{array}$ \\
\hline $\mathrm{A}$ & 200 & 0.10 & 100.0 & 1.35 & 0.098 & 0.42 \\
$\mathrm{~B}$ & 200 & 0.15 & 90.9 & 1.28 & 0.106 & 0.50 \\
$\mathrm{C}$ & 240 & 0.20 & 41.7 & 0.88 & 0.238 & 0.50 \\
$\mathrm{D}$ & 400 & 0.20 & 25.0 & 0.77 & 0.491 & 0.37 \\
\hline
\end{tabular}

It should be noted that in the case of the work with MQL, proceeding from point B to $\mathrm{C}$ means an increase of $118 \%$ in productivity and a decrease of $31 \%$ in energy consumption, but the consumption of the cutting tools increases by $124 \%$. This type of analysis should be complemented with the corresponding cost evaluation for the lubrication regime.

\section{Conclusions}

The study carried out shows that there is a statistically significant effect of cutting speed and feed rate on the initial progression of wear on the impact surface of BIDEMICS JX1 cutting tools, coinciding with recent studies [25]. The initial progression of wear on the incidence surface has a direct relationship with the logarithms of the cutting speed and feed rate. In this case, the cutting speed is the parameter with the highest incidence, in accordance with that reported in similar studies [17]. 
For the analysis of the convergence of each Pareto front obtained in each replica, the hypervolume was taken as the front quality metric. In this sense, both for dry machining and MQL, the coefficient of variation is $0.3 \%$ and $0.2 \%$, respectively, which indicates a high coincidence of the faces obtained. Thus, it is evidenced that the results are close enough to the true Pareto front to be used for practical purposes.

The sets and Pareto boundaries obtained provide a range of optimal solutions that can be applied in different workshops according to their needs. For decision-making, solution A should be selected if lower consumption of the cutting tools is desired, without considering productivity and energy consumption. Solution D represents the one with the highest productivity and lowest energy consumption. Points $B$ and $C$ are compensation solutions. It should be noted that proceeding from point $B$ to $C$ means a $118 \%$ increase in productivity and a $31 \%$ decrease in energy consumption, but the consumption of the cutting tools increases by $124 \%$. This type of analysis must be complemented by the corresponding cost evaluation.

The mathematical model of the optimization of the cutting regime $(\mathrm{V}, \mathrm{f})$ using a genetic algorithm based on NSGA-II during dry turning and with the use of MQL, with BIDEMICS JX1 ceramic tools from AISI 316L steel, allowed for the identification of the solutions more relevant for minimizing the initial progression of cutting tool wear and the energy consumed. Productivity was maximized, guaranteeing surface roughness values according to the ISO 7206-2 standard. The approach uses a new generation genetic algorithm design, in contrast to similar studies $[5,19,20,27]$.

Author Contributions: Conceptualization, R.d.R.-A., R.P.-R., M.R.S. and R.Q.; investigation, R.R.A., R.P.R. and P.d.C.Z.R.; software, R.Q. and M.R.S.; validation, R.Q. and M.R.S.; writing-original draft preparation, R.d.R.-A., R.P.-R. and P.d.C.Z.R.; data curation, R.d.R.-A., R.P.-R. and R.Q.; supervision, M.R.S. and R.Q. All authors have read and agreed to the published version of the manuscript.

Funding: The authors thank the Government of Mexico for granting the Scholarship through the Secretary of Foreign Relations, which allowed for the stay at the Tecnológico de Monterrey to carry out the research, and Honeywell Aerospace de México for the logistical support.

Institutional Review Board Statement: Not applicable.

Informed Consent Statement: Not applicable.

Data Availability Statement: Data sharing is not applicable to this article.

Conflicts of Interest: The authors declare no conflict of interest.

\section{References}

1. Nouri, A.; Wen, C. Stainless steels in orthopedics. In Structural Biomaterials: Properties, Characteristics and Selection; Wen, C., Ed.; Woodhead: Cambridge, UK, 2021; pp. 67-101.

2. Lamichhane, Y.; Singh, G.; Bhui, A.S.; Mukhiya, P.; Kumar, P.; Thapa, B. Surface modification of 3161 SS with hap nano-particles using pmedm for enhanced biocompatibility. Mater. Today: Proc. 2019, 15, 336-343. [CrossRef]

3. Nomani, J.; Pramanik, A.; Hilditch, T.; Littlefair, G. Machinability study of first generation duplex (2205), second generation duplex (2507) and austenite stainless steel during drilling process. Wear 2013, 304, 20-28. [CrossRef]

4. Nur, R.; Noordin, M.Y.; Izman, S.; Kurniawan, D. Machining parameters effect in dry turning of AISI 3161 stainless steel using coated carbide tools. Proc. Inst. Mech. Eng. E J. Process. Mech. Eng. 2015, 231, 676-683. [CrossRef]

5. Kara, F.; Aslantaş, K.; Çiçek, A. Prediction of cutting temperature in orthogonal machining of AISI 3161 using artificial neural network. Appl. Soft Comput. 2016, 38, 64-74. [CrossRef]

6. Maurotto, A.; Tsivoulas, D.; Gu, Y.; Burke, M.G. Effects of machining abuse on the surface properties of AISI 3161 stainless steel. Int. J. Press. Vess. Pip. 2017, 151, 35-44. [CrossRef]

7. Fernández-Abia, A.I.; García, J.B.; López-de-Lacalle, L.N. High-performance machining of austenitic stainless steels. In Machining and Machine-Tools; Davim, J.P., Ed.; Woodhead: Cambridge, UK, 2013; pp. 29-90.

8. Markopoulos, A.P.; Galanis, N.I.; Karkalos, N.E.; Manolakos, D.E. Precision CNC machining of femoral component of knee implant: A case study. Machines 2018, 6, 10. [CrossRef]

9. Lin, W.S. The study of high speed fine turning of austenitic stainless steel. J. Achiev. Mater. Manuf. Eng. 2008, 27, 191-194.

10. Kadadevaru, S.G.; Kulkarni, V.N.; Gaitonde, V.N. A review on surface integrity studies in machining of biomedical alloys. Mater. Today: Proc. 2019, 18, 5494-5501. [CrossRef] 
11. Ciftci, I. Machining of austenitic stainless steels using CVD multi-layer coated cemented carbide tools. Tribol. Int. 2006, 39, 565-569. [CrossRef]

12. Maruda, R.W.; Legutko, S.; Krolczyk, J.B.; Wojciechowski, S.; Kot, W.; Hloch, S.; Klichová, D.; Krolczyk, G.; Chattopadhyaya, S.; Ruppenthalová, L. The influence of the application of ep additive in the minimum quantity cooling lubrication method on the tool wear and surface roughness in the process of turning 316L steel. In Advances in Manufacturing Engineering and Materials; Springer International: Manhattan, NY, USA, 2019; pp. 254-263.

13. Fernández-Lucio, P.; Pereira-Neto, O.; Gómez-Escudero, G.; Amigo-Fuertes, F.J.; Fernández-Valdivielso, A.; López-de-Lacalle, L.N. Roughing milling with ceramic tools in comparison with sintered carbide on nickel-based alloys. Coatings 2021, 11, 734. [CrossRef]

14. Yu, W.; Ming, W.; An, Q.; Chen, M. Cutting performance and wear mechanism of honeycomb ceramic tools in interrupted cutting of nickel-based superalloys. Ceram. Int. 2021, 47, 18075-18083. [CrossRef]

15. Sisodiya, M.S.; Bajpai, V. An insight: Machining of titanium alloys \& associated tool wear. IOP Conf. Ser. Mater. Sci. Eng. 2021, 1017, 012013.

16. Vereschaka, A.A.; Grigoriev, S.N.; Volosova, M.A.; Batako, A.; Vereschaka, A.S.; Sitnikov, N.N.; Seleznev, A.E. Nano-scale multi-layered coatings for improved efficiency of ceramic cutting tools. Int. J. Adv. Manuf. Technol. 2017, 90, 27-43. [CrossRef]

17. Memarianpour, M.; Niknam, S.A.; Turenne, S.; Balazinski, M.; Fujita, H.; Nguyen, D.; Vu, N.; Banh, T.; Puta, H. Initial tool wear mechanism in dry and lubricated turning of Inconel 718. In Advances in Engineering Research and Application; Springer International: Manhattan, NY, USA, 2019; pp. 390-397.

18. Aramesh, M.; Shaban, Y.; Yacout, S.; Attia, M.H.; Kishawy, H.A.; Balazinski, M. Survival life analysis applied to tool life estimation with variable cutting conditions when machining titanium metal matrix composites (Ti-MMCs). Mach. Sci. Technol. 2016, 20, 132-147. [CrossRef]

19. Amouzgar, K.; Bandaru, S.; Andersson, T.; Ng, A.H.C. Metamodel-based multi-objective optimization of a turning process by using finite element simulation. Eng. Optim. 2020, 52, 1261-1268. [CrossRef]

20. Eskandari, B.; Davoodi, B.; Ghorbani, H. Multi-objective optimization of parameters in turning of N-155 iron-nickel-base superalloy using gray relational analysis. J. Braz. Soc. Mech. Sci. Eng. 2018, 40, 233. [CrossRef]

21. Gunantara, N. A review of multi-objective optimization: Methods and its applications. Cogent Eng. 2018, 5, 1502242. [CrossRef]

22. NTK Cutting Tools. New Products; NTK Cutting Tools: Kamaki, Japan, 2016; Volume 2, pp. $2-4$.

23. Mirjalili, S.; Dong, J.S. Multi-Objective Optimization Using Artificial Intelligence Techniques; Springer International: Cham, Switzerland, 2020; 58p.

24. Balogun, V.A.; Edem, I.F.; Mativenga, P.T. Process mechanisms and their relevance for sustainable machining processes. Procedia Manuf. 2019, 35, 361-366. [CrossRef]

25. Luan, X.; Zhang, S.; Li, J.; Mendis, G.; Zhao, F.; Sutherland, J.W. Trade-off analysis of tool wear, machining quality and energy efficiency of alloy cast iron milling process. Procedia Manuf. 2018, 26, 383-393. [CrossRef]

26. Kumar, C.S.; Patel, S.K. Experimental and numerical investigations on the effect of varying AlTiN coating thickness on hard machining performance of al2o3-ticn mixed ceramic inserts. Surf. Coat. Technol. 2017, 309, 266-281. [CrossRef]

27. Labidi, A.; Tebassi, H.; Belhadi, S.; Khettabi, R.; Yallese, M.A. Cutting conditions modeling and optimization in hard turning using RSM, ANN and desirability function. J. Fail. Anal. Prev. 2018, 18, 1017-1033. [CrossRef]

28. Mohd Ali, A.; Ahmad Azhar, A.Z.; Ratnam, M.M.; Ahmad, Z.A. Wear analysis of ZTA-MgO ceramic cutting inserts on stainless steel 316L machining. Adv. Mater. Res. 2015, 1087, 101-105. [CrossRef]

29. Mohd Ali, A.; Abdullah, N.S.; Ratnam, M.; Ahmad, Z.A. The cutting speed influences on tool wear of ZTA ceramic cutting tools and surface roughness of work material stainless steel 316L during high speed machining. Mater. Sci. Forum 2016, 840, 315-320. [CrossRef]

30. Ahmad Azhar, A.Z.; Mokhtar, M.; Ratnam, M.M.; Ahmad, Z.A. Effects of tin single layer coating on the wear of ZTA cutting inserts and surface roughness of workpiece. Mater. Sci. Forum 2017, 888, 52-56. [CrossRef]

31. Karkalos, N.E.; Markopoulos, A.P.; Davim, J.P. Computational Methods for Application in Industry 4.0, 1st ed.; Springer International: Cham, Switzerland, 2019; 67p.

32. Jiang, S.; Ong, Y.S.; Zhang, J.; Feng, L. Consistencies and contradictions of performance metrics in multiobjective optimization. IEEE Trans. Cybern. 2014, 44, 2391-2404. [CrossRef] 